\title{
Frequency and causes of anemia in Lymphoma patients
}

\author{
Tahira Yasmeen ${ }^{1}$, Jamshed $A$ Ii $^{2}$, \\ Khadeeja Khan ${ }^{3}$, Neelam Siddiqui ${ }^{4}$
}

\begin{abstract}
Objective: Purpose of this study was to find out frequency of anemia and its causes in newly diagnosed treatment naive lymphoma patients.

Methods: We retrospectively studied all lymphoma patients ( $>18$ years age) diagnosed and treated at Shaukat Khanum Memorial Cancer Hospital and Research Centre, from January 2016 till January 2017. The data was collected from electronic Hospital Information System. Descriptive statistics were done by using summary measures for categorical variables as well as continuous variables.

Results: Out of a total 408 patients, 272 were males and 136 females. Median age of patients was 33 years (18-76). Hodgkin lymphoma (HL) and diffuse large B cell lymphoma (DLBCL) were the diagnosis in 201 and 134 patients respectively; rest of the patients had low grade lymphomas. Anemia was present in 184 (45\%) patients. Anemia of chronic disease was the commonest cause of anemia and was present in 61 (33.1\%) patients. Remaining patients had anemia secondary to marrow involvement $50(27.17 \%)$; iron deficiency anemia, Vitamin B-12 deficiency anemia and hemolytic anemia were the causes in $7.6,1.6 \%$, \% and $0.54 \%$ respectively.

Conclusion: Anemia is a common feature in newly diagnosed lymphoma patients with anemia of chronic disease as the commonest cause. It is more frequent in patients with higher stages of lymphoma especially when bone marrow is involved by lymphoma. Since anemia is an important adverse prognostic factor for the outcome of lymphoma patients, work up for anemia prior to initiation of chemotherapy should be done in every lymphoma patient in order to help improve the management of these patients.
\end{abstract}

KEYWORDS: Anemia, Hodgkin lymphoma, Non Hodgkin lymphoma.

doi: https://doi.org/10.12669/pjms.35.1.91

How to cite this:

Yasmeen T, Ali J, Khan K, Siddiqui N. Frequency and causes of anemia in Lymphoma patients. Pak J Med Sci. 2019;35(1):61-65. doi: https://doi.org/10.12669/pjms.35.1.91

This is an Open Access article distributed under the terms of the Creative Commons Attribution License (http://creativecommons.org/licenses/by/3.0), which permits unrestricted use, distribution, and reproduction in any medium, provided the original work is properly cited.

1. Dr. Tahira Yasmeen, FCPS (Medicine), Fellow Medical Oncology,

2. $\quad$ Dr. Jamshed Ali, FCPS ( Medicine)

FCPS (Medical Oncology), Senior Instructor,

3. Dr. Khadeeja Khan, MBBS,

Medical Officer,

4. Dr. Neelam Siddiqui, MRCP, FRCP, CCST (Medical Oncology), Consultant Oncologist,

1-4: Department of Medical Oncology, Shaukat Khanum Memorial Cancer Hospital and Research Centre, Lahore, Pakistan.

Correspondence:

Dr. Tahira Yasmeen,

Shaukat Khanum Memorial Cancer, Hospital and Research Centre,

7-A Block, R-3, Johar Town, Lahore, Pakistan.

E-mail: drtahirayasmeen@yahoo.com

* Received for Publication:

June 8, 2018

* $1^{\text {st }}$ Revision Received:

* $2^{\text {nd }}$ Revision Received:

October 25, 2018

* Final Revision Accepted:

November 22, 2018

\section{INTRODUCTION}

Lymphomas represent one of the commonest malignancies. There has been an increase in non hodgkin lymphoma (NHL) cases in past few decades and among B cell lymphomas diffuse large B cell lymphoma (DLBCL) is the commonest type. ${ }^{1}$ Anemia is frequently encountered in lymphoma patients and even observed before patients are started on chemotherapy and also in the absence of bone marrow involvement. ${ }^{2}$ It is a presenting feature in approximately $40 \%$ of patients with Hodgkin's lymphoma (HL) ${ }^{3}$ and is considered an important adverse prognostic factor for outcomes of therapy ${ }^{4-6}$ especially in the background of bone marrow involvement which is yet another factor associated 
with poor prognosis. ${ }^{7}$ In patients with DLBCL anemia was found to be predictive of event free and disease free survival. It was further noted that those patients who were anemic even at six months after rituximab based therapy had higher risk for disease relapse ${ }^{8,9}$ In addition to its association with poor prognosis in cancer patients there is correlation between levels of hemoglobin and quality of life. ${ }^{10}$

There are multiple factors responsible for anemia in patients with lymphoproliferative disorders, including anemia of chronic disease, iron deficiency anemia, nutritional deficiencies, autoimmune hemolytic anemia, marrow infiltration and blood loss. ${ }^{11}$ Several inflammatory mediators have been identified such as interleukin 1, gamma interferon and tumor necrosis factor that inhibit erythropoiesis. ${ }^{12,13}$ Abnormal iron utilization, inappropriately low serum erythropoietin levels and decreased marrow response to erythropoietin are also responsible for anemia in these patients. ${ }^{4}$ In a study by Tisi MC et al. raised interleukin 6 was identified as major factor in development of anemia in patients with DLBCL. ${ }^{14}$ In an individual patient, more than one of these factors may be in play and responsible for anemia. There is very limited data on frequency of anemia in lymphoid malignancies in developing countries, which is very crucial to identify and treat appropriately. Aim of this study was to find out frequency and causes of anemia in lymphoma patients diagnosed over one year in our hospital.

\section{METHODS}

Newly diagnosed treatment naïve adult (18 years and above) lymphoma patients who presented to Shaukat Khanum Memorial Cancer Hospital and Research Centre from January 2016 till January 2017 were included in this study. Lymphoma was diagnosed by histopathology from nodal or involved tissue biopsy. Medical records of all enrolled patients in study period were retrospectively analyzed. Data was collected regarding age, gender, diagnosis and stage at the time of diagnosis. Anemia was defined as hemoglobin $(\mathrm{Hb})$ of $<11.5 \mathrm{gm} / \mathrm{dl}$ and it was categorized into mild $(11-11.5 \mathrm{gm} / \mathrm{dl})$, moderate $(8-10.9 \mathrm{gm} / \mathrm{dl})$ and severe $(<8 \mathrm{gm} / \mathrm{dl})$. It was also recorded whether bone marrow involvement was present or not at time of diagnosis. Data was collected for red blood cell indices including mean corpuscular volume (MCV), mean corpuscular hemoglobin $(\mathrm{MCH})$, and mean corpuscular hemoglobin concentration (MCHC). Reticulocyte count, serum iron levels, total iron binding capacity (TIBC), serum ferritin, vitamin B 12 levels, RBC folate levels were recorded. Coomb's test was also recorded for patients in whom this investigation was done at the time of diagnosis. Reticulocyte count was categorized into $<0.5,0.5-2$ and $>2$. MCV, $\mathrm{MCH}, \mathrm{MCHC}$, serum iron, TIBC, serum ferritin, vitamin $\mathrm{B} 12$ and $\mathrm{RBC}$ folate were categorized into low, normal or high except in Coomb's test which was categorized as positive, negative or not done. All available parameters were interpreted in individual patient and cause of anemia identified accordingly. Iron deficiency anemia was defined by low ferritin, low iron and raised TIBC, while vitamin B12 and folate deficiency was ascertained by their low levels. Statistical Analysis: Statistical analysis was carried out using the SPSS software (version 20.0; SPSS, Chicago, IL, USA). Continuous variables were stated as Mean \pm SD and categorical variables were computed as frequencies and percentages. Anemia frequency was calculated by using simple prevalence formula as (number of patients in each diagnosis / total number of cases). Patients with incomplete data were also analyzed in final analysis.

\section{RESULTS}

The baseline description of 408 lymphoma patients with a mean age and standard deviation of $33.04 \pm 11.50$ years in which $197(48.3 \%)$ were 30 years or younger (Table-I). The majority $(66.7 \%)$ of participants were male with $50 \%$ diagnosed with HL. Among all patients $14.4 \%$ had stage I disease and $48.03 \%$ had stage IV disease. Anemia was present in $45 \%$ patients among which most of the anemic patients were moderately anemic (30.4\%). Anemia was present in $55.97 \%$ males and $44.03 \%$ females. Anemia was observed in $53.23 \% \mathrm{HL}$ patients and in $40.3 \%$ patients with DLBCL patients as shown in Table-II. Severity of anemia was moderate in most of anemic patients as shown in Table-III.

It was observed that anemia was more common in patients with stage IV disease (59.1\% patients) with decreasing frequency in lower stages of lymphoma i.e. $38.96 \%, 26.3 \%$ and $30.5 \%$ in stage III, II and I respectively. Severity of anemia was moderate in all stages (Fig.1). Anemia of chronic disease was the most common cause of anemia and was present in $33.1 \%$ of patients and marrow involvement was the second common cause of anemia (27.17\% patients). Iron deficiency anemia, B 12 deficiency and hemolytic anemia were the causes of anemia in $7.6 \%$, $1.6 \%$ and $0.54 \%$ respectively in anemic patients. In $29.8 \%$ patient's cause of anemia could not be identified due to incomplete anemia work up at baseline. Causes of anemia were analyzed separately as well 
Table-I: Baseline characteristics, frequency and causes of anemia in lymphoma patients (N-408).

\begin{tabular}{|c|c|c|c|}
\hline Variables & Frequency - N (\%) & Variables & Frequency - N (\%) \\
\hline \multicolumn{2}{|c|}{ Age in years } & \multicolumn{2}{|c|}{ Extra Nodal involvement } \\
\hline $18-30$ & $197(48.3 \%)$ & Absent & $283(69.4 \%)$ \\
\hline $31-40$ & $131(32.1 \%)$ & Present & $125(30.6 \%)$ \\
\hline Above 40 & $80(19.6 \%)$ & Bone marrow in & ement \\
\hline \multicolumn{2}{|c|}{ Sex } & Absent & $306(75.0 \%)$ \\
\hline Male & $272(66.7 \%)$ & Present & $83(20.3 \%)$ \\
\hline Female & $136(33.3 \%)$ & Not Done & $19(4.7 \%)$ \\
\hline \multicolumn{2}{|c|}{ Diagnosis } & \multicolumn{2}{|c|}{ Bulky disease } \\
\hline Hodgkin Lymphoma & $201(49.3 \%)$ & Absent & $247(60.5 \%)$ \\
\hline \multicolumn{4}{|l|}{ Non Hodgkin Lymphomas } \\
\hline DLBCL* & $134(32.8 \%)$ & Present & $161(39.5 \%)$ \\
\hline Follicular Lymphoma & $18(4.4 \%)$ & \multirow{2}{*}{\multicolumn{2}{|c|}{ Anemia }} \\
\hline Burkitts lymphoma & $16(3.9 \%)$ & & \\
\hline Marginal zone lymphoma & $11(2.7 \%)$ & Absent & $224(54.9 \%)$ \\
\hline Natural Killer cells & $4(1.0 \%)$ & Present & $184(45.1 \%)$ \\
\hline Others $^{\#}$ & $24(5.9 \%)$ & \multicolumn{2}{|c|}{ Grades of Anemia } \\
\hline \multicolumn{2}{|c|}{ Stage } & No Anemia & $224(54.9 \%)$ \\
\hline I & $59(14.5 \%)$ & Mild Anemia & $37(9.1 \%)$ \\
\hline II & $76(18.6 \%)$ & Moderate Anemia & $124(30.4 \%)$ \\
\hline III & $77(18.9 \%)$ & Severe Anemia & $23(5.6 \%)$ \\
\hline IV & $196(48.0 \%)$ & \multicolumn{2}{|c|}{ Causes of Anemia } \\
\hline \multicolumn{2}{|c|}{ B-Symptoms } & Anemia of chronic disease & $61(33.1 \%)$ \\
\hline Absent & $128(31.4 \%)$ & Marrow involvement anemia & $50(27.17 \%)$ \\
\hline Present & $280(68.6 \%)$ & Iron deficiency anemia & $14(7.6 \%)$ \\
\hline \multirow{2}{*}{\multicolumn{2}{|c|}{ Splenomegaly }} & B-12 deficiency anemia & $3(1.6 \%)$ \\
\hline & & Hemolytic anemia & $1(0.54 \%)$ \\
\hline Absent & $290(71.1 \%)$ & Incomplete work up & $55(29.89 \%)$ \\
\hline Present & $118(28.9 \%)$ & & \\
\hline
\end{tabular}

*Diffuse large B-cell lymphoma, \# Lymphomatoid granulomatosis, Mantle cell lymphoma, Gastric MALT, anaplastic large cell lymphoma, T cell rich large B cell lymphoma.

in all HL and DLBCL patients. The most prevalent cause of anemia in HL and DLBCL individually was anemia of chronic disease and was present in 35 and 18 patients respectively. Anemia secondary to bone marrow involvement was the second most common cause identified in these patients and was found in 30 patients in HL and in 10 patients with
DLBCL. Anemia secondary to iron deficiency was the third cause in HL and DLBCL patients.

\section{DISCUSSION}

Anemia is commonly encountered in cancer patients; however this problem is greater in lymphoma and multiple myeloma. In patients 


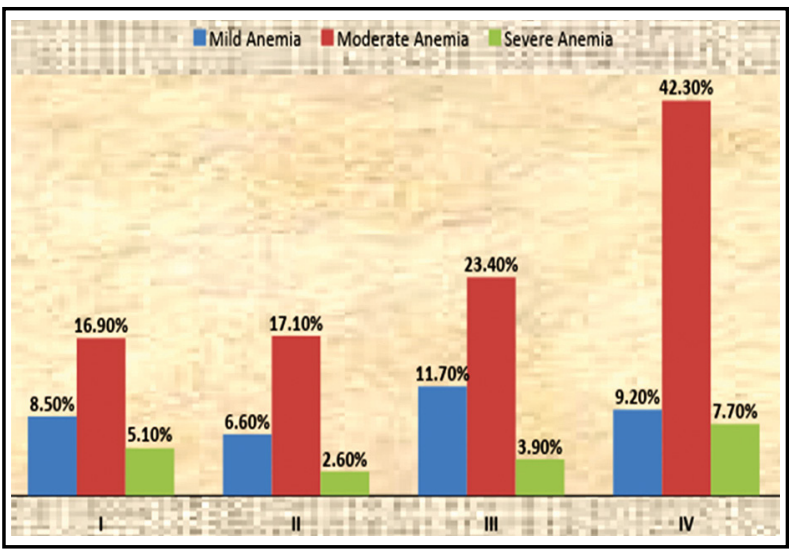

Fig.1: Severity of anemia in stages I-IV of lymphoma.
Table-II: Frequency of anemia in different type of lymphomas.

\begin{tabular}{lc}
\hline Diagnosis & Prevalence \\
\hline Hodgkin lymphoma & $53.23 \%$ \\
Follicular Lymphoma & $44.5 \%$ \\
DLBCL* & $40.3 \%$ \\
Burkitts lymphoma & $37.5 \%$ \\
Marginal zone lymphoma & $18.2 \%$ \\
Natural killer cells lymphoma & $25 \%$ \\
Others\# & $25 \%$ \\
\hline
\end{tabular}

*Diffuse large B-cell lymphoma, \# Lymphomatoid granulomatosis, Mantle cell lymphoma,

Gastric MALT, Anaplastic large cell lymphoma, T cell rich large B cell lymphoma.

Table-III: Severity of anemia in different type of lymphomas.

\begin{tabular}{lccc}
\hline Diagnosis & Mild Anemia N (\%) & Moderate Anemia N (\%) & Severe Anemia N (\%) \\
\hline Hodgkin lymphoma (201) & $16(8.0)$ & $75(37.3)$ & $16(8.0)$ \\
DLBCL*(134) & $13(9.7)$ & $38(28.5)$ & $3(2.2)$ \\
Follicular Lymphoma (18) & $4(22.2)$ & $3(16.7)$ & $1(5.6)$ \\
Burkitts lymphoma (16) & $1(6.2)$ & $5(31.2)$ & $0(0.0)$ \\
Marginal zone lymphoma (11) & $2(18.2)$ & $0(0.0)$ & $0(0.0)$ \\
Natural killer cell lymphoma (4) & $0(0.0)$ & $1(25.0)$ & $0(0.0)$ \\
Others\# & $1(4.2)$ & $2(8.3)$ & $3(12.5)$ \\
\hline
\end{tabular}

*Diffuse large B-cell lymphoma \# Lymphomatoid granulomatosis, Mantle cell lymphoma,

Gastric MALT, anaplastic large cell lymphoma, T cell rich large B cell lymphoma.

with lymphoma, anemia has been shown to be an independent prognostic factor with worse outcome of therapy and increased mortality. ${ }^{2,11,15}$ Apart from its impact on survival, anemia also impairs quality of life of these patients by causing fatigue, shortness of breath, cardiovascular complications, cognitive impairment and poor performance status. Evaluation of the incidence and etiology of pretreatment anemia could help improve the prognostication and management of these patients.

According to a report by European Cancer Anemia Survey (ECAS), 39\% of lymphoma patients were anemic at the time they were enrolled in the survey and only $47.3 \%$ of the anemic patients received any treatment for anemia during this survey, emphasizing the need to identify anemia at the time of diagnosis and adequately treating it in these patients. ${ }^{16,17}$ There is inadequate data regarding prevalence and etiology of anemia in lymphoma patients in our part of the world, especially Pakistan.

In this study our aim was to find out frequency and causes of anemia in newly diagnosed lymphoma patients. Out of a total of 408 lymphoma patients, almost half $(45 \%)$ had anemia at presentation. Similar prevalence of anemia $(42.4 \%)$ was found in one prospective study by Gosh et al from India ${ }^{11}$, while other studies of non-Hodgkin's lymphoma reported their figures at $32 \%$ and $35.3 \% .^{2,4}$ More lymphoma patients were male $(66.7 \%)$ as compared to only $33.33 \%$ females. Another study from Pakistan also suggested that the prevalence of NHL was higher in males (69\%) than in females $(31 \%) .{ }^{18}$ Although male population was higher in number in our study but anemia was more frequent in female patients. Higher prevalence of anemia in females has also been reported in other similar studies, which likely reflects ongoing losses in young females in reproductive age group..$^{4,11}$

Multiple factors may be involved at the same time in causing anemia in lymphoma patients. Anemia of chronic disease was identified as the most common cause of anemia in our patients as well as in other studies. The pathogenesis behind anemia of chronic disease is likely bone marrow erythroid hypoplasia, shortened red cell survival,

Table-IV: Severity of anemia in stages I-IV of lymphoma.

\begin{tabular}{lcccc}
\hline & $I$ & $I I$ & $I I I$ & $I V$ \\
\hline Mild Anemia & $8.50 \%$ & $6.60 \%$ & $11.70 \%$ & $9.20 \%$ \\
Moderate Anemia & $16.90 \%$ & $17.10 \%$ & $23.40 \%$ & $42.30 \%$ \\
Severe Anemia & $5.10 \%$ & $2.60 \%$ & $3.90 \%$ & $7.70 \%$ \\
\hline
\end{tabular}


decreased erythropoietin production and high inflammatory cytokine production by lymphoma cells., ${ }^{2,21}$ More than half of our patients (59.1\%) with anemia had stage IV disease This correlation of anemia with higher stages of lymphoma has been reported in other studies as well., ${ }^{4,11}$ In developing countries majority of the patients are diagnosed with advanced stages of disease and this can be one factor for high prevalence of anemia, with bone marrow involvement as one of the causative factor. Interestingly our study revealed that anemia of chronic disease, anemia secondary to bone marrow involvement and iron deficiency anemia remained the major causes of anemia when HL and DLBCL patients were analyzed separately.

Limitations of the study: It was a retrospective study, in which the required tests to further characterize the cause of anemia were not done in some of the patients i.e. incomplete data about vitamin B12, folate, reticulocyte count and hemolytic profile. Secondly it was a single center study which limits its applicability on the entire population with lymphoma.

\section{CONCLUSION}

The results of our study suggest that anemia is quite common in newly diagnosed lymphoma patients. The fact that anemia not only has an impact on survival and heralds poor prognosis, it is also detrimental for the quality of life of these patients. It is imperative that anemia should be identified, appropriately investigated and treated in all lymphoma patients at presentation. This simple step could ultimately help in overall better outcome in these patients.

Acknowledgments: Mr. Abu Bakar contributed significantly in statistical analysis of data. Mr. Abul Hasan contributed in SPSS formatting of data.

Financial Disclosures: This study is not funded.

Disclosure of Conflict of Interest: All authors have no conflicts of interest to disclose.

\section{REFERENCES}

1. Lee SJ, Suh CW, Lee SI, Kim WS, Lee WS, Kim HJ, et al. Clinical characteristics, pathological distribution, and prognostic factors in nonHodgkin lymphoma of Waldeyer's ring: nationwide Korean study. Korean J Intern Med. 2014;29(3):352. doi:10.3904/kjim.2014.29.3.352.

2. Moullet I, Salles G, Ketterer N, Dumontet C, Bouafia F, NeidhartBerard EM, et al. Frequency and significance of anemia in nonHodgkin's lymphoma patients. Ann Oncol. 1998;9(10):1109-1115.

3. Cuccaro A, Bartolomei F, Cupelli E, Galli E, Giachelia M, Hohaus S. Prognostic factors in hodgkin lymphoma. Mediterr J Hematol Infect Dis. 2014;6(1). doi: 10.4084/MJHID.2014.053.

4. Morrow TJ, Volpe S, Gupta S, Tannous RE, Fridman M. Anemia of cancer in intermediate-grade non-Hodgkin's lymphoma. Southern Med J. 2002;95(8):889-896.
5. Morel P, Lepage E, Brice P, Dupriez B, D'Agay MF, Fenaux P, et al. Prognosis and treatment of lymphoblastic lymphoma in adults: a report on 80 patients. J Clin Oncol. 1992;10(7):1078-1085. doi: 10.1200/JCO.1992.10.7.1078

6. Bremnes RM, Bremnes Y, Donnem T. High-grade non-Hodgkin's lymphoma treated in northern Norway: treatment, outcome, and prognostic factors. Acta Oncologica. 1999;38(1):117-124. doi: 10.1080/028418699431906.

7. Bartl R, Frisch B, Burkhardt R, Kettner G, Mahl G, Fateh- Moghadam A et al. Assessment of bone marrow histology in the malignant lymphomas (non- Hodgkin's): correlation with clinical factors for diagnosis, prognosis, classification and staging. Br J Haematol. 1982;51(4):511-530. doi: 10.3109/10428194.2013.802314.

8. Troppan KT, Melchardt T, Deutsch A, Schlick K, Stojakovic T, Bullock MD et al. The significance of pretreatment anemia in the era of R-IPI and NCCN-IPI prognostic risk assessment tools: a dual center study in diffuse large B-cell lymphoma patients. Eur J Haematol. 2015;95(6):538-544. doi: 10.1111/ejh.12529.

9. Hong J, Woo HS, Kim H, Ahn HK, Sym SJ, Park J et al. Anemia as a useful biomarker in patients with diffuse large B-cell lymphoma treated with R-CHOP immunochemotherapy. Cancer Sci. 2014;105(12):1569-1575. doi: 10.1111/cas.12544.

10. Ludwig H, Evstatiev R, Kornek G, Aapro M, Bauernhofer T, Buxhofer-Ausch $\mathrm{V}$ et al. Iron metabolism and iron supplementation in cancer patients. Wiener Klinische Wochenschrift. 2015;127(2324):907-919. doi: 10.1007/s00508-015-0842-3.

11. Ghosh J, Singh RK, Saxena R, Gupta R, Vivekanandan S, Sreenivas V et al. Prevalence and aetiology of anaemia in lymphoid malignancies. Natl Med J India. 2013;26(2):79-81.

12. Mamus SW, Beck-Schroeder S, Zanjani ED. Suppression of normal human erythropoiesis by gamma interferon in vitro. Role of monocytes and T lymphocytes. J Clin Invest. 1985;75(5):1496-1503. doi: $10.1172 /$ JCI 111853

13. Means RT, Dessypris EN, Krantz SB. Inhibition of human erythroid colony-forming units by interleukin-1 is mediated by $\mathrm{y}$ - interferon. J cell Physiol. 1992 Jan 1; 150(1):59-64. doi: 10.1002/jcp.1041500109.

14. Tisi MC, Bozzoli V, Giachelia M, Massini G, Ricerca BM, Maiolo E, et al. Anemia in diffuse large B-cell non-Hodgkin lymphoma: the role of interleukin-6, hepcidin and erythropoietin. Leukemia Lymphoma. 2014;55(2):270-275. doi:10.3109/10428194.2013.802314.

15. Hasenclever D, Diehl V, Armitage JO, Assouline D, Björkholm M, Brusamolino E, et al. A prognostic score for advanced Hodgkin's disease. N Eng J Med. 1998; 339(21):1506-1514. doi: 10.1056/ NEJM199811193392104.

16. Naoum FA. Iron deficiency in cancer patients. Revista Brasileira de Hematologia e Hemoterapia. 2016;38(4):325-330. doi: 10.1016/j. bjhh.2016.05.009.

17. Birgegård G, Gascón P, Ludwig H. Evaluation of anemia in patients with multiple myeloma and lymphoma: findings of the European Cancer Anaemia Survey. Euro J Haematol. 2006;77(5):378-386. doi: 10.1111/j.1600-0609.2006.00739.x.

18. Bukhari U, Jamal S, Lateef F. Non Hodgkin lymphoma - A study. Pak Oral Dental J. 2015;35(3):412-415.

19. Zucker S. Anemia in cancer. Cancer Invest. 1985;3(3):249-260. doi: 10.3109/07357908509039786.

20. Jelkmann W, Pagel H, Wolff M, Fandrey J. Monokines inhibiting erythropoietin production in human hepatoma cultures and in isolated perfused rat kidneys. Life Sci. 1992;50(4):301-308. doi: 10.1016/0024-3205(92)90338-P.

21. Faquin WC, Schneider TJ, Goldberg MA. Effect of inflammatory cytokines on hypoxia-induced erythropoietin production. Blood. 1992;79(8):1987-1994.

Authors' Contribution: TY: Designed, did literature review, data interpretation, statistical analysis and manuscript writing. JA: Did literature search, data interpretation. KK: Did all the data collection and helped in data interpretation. NS: Conceived the study idea and did final manuscript review. TY: Takes the responsibility and is accountable for all aspects of the work in ensuring that questions related to the accuracy or integrity of any part of the work are appropriately investigated and resolved. 